\title{
PENGARUH TERPAAN MEDIA SOSIAL YOUTUBE DAN INTERAKSI ANTARSOSIAL TERHADAP PERILAKU IMITASI REMAJA PUTRI (Studi Kasus Video Clip Blackpink-Ddu Du Ddu Du)
}

\author{
Rahayu Marini Hakim ${ }^{1}$, Ahmad Fatoni ${ }^{2 *}$ \\ 1,2 Fakultas Ilmu Komunikasi Universitas Gunadarma \\ Jl. Margonda Raya No. 100, Depok 16424, Jawa Barat \\ Email: 'rahayumarinih@gmail.com; ${ }^{2}$ ahmad_fatoni@staff.gunadarma.ac.id \\ *Penulis korespondensi
}

\begin{abstract}
ABSTRAK
Dalam penelitian ini terdapar tiga variabel yaitu variabel Terpaan Media dan Interaksi Sosial sebagai Independent dan variabel Perilaku Imitasi sebagai Dependent. Tujuan penelitian ini adalah: (1). Untuk mengetahui dan menganalisis Pengaruh media sosial Youtube konten K-POP terhadap perilaku imitasi remaja putri. (2) Untuk mengetahui dan menganalisis pengaruh Interaksi Sosial terhadap perilaku imitasi remaja putri. (3) Untuk mengetahui dan menganalisis pengaruh media sosial Youtube konten K-POP dan Interaksi Sosial terhadap perilaku imitasi remaja putri. Alat analisis yang digunakan adalah regresi linier berganda dengan bantuan sofware statistik SPSS versi 20. Teknik dalam pengambilan sampel dalam penelitian ini dilakukan dengan followers akun instagram @ zonablackpink dengan digunakan sebanyak 395 responden. Metode yang digunakan dalam penelitian ini adalah metode kuantitatif untuk mengetahui pengaruh ataupun juga hubungan antar dua variabel atau lebih. Teknik pengunpulan data menggunakan observasi, kuesioner (angket) dan kepustakaan. Hipotesis dari penelitian ini adalah ada pengaruh yang signifikan antara terpaan media, interaksi sosial terhadap perilaku imitasi pada remaja putri. Diantara pengaruh Terpaan Media dan Interaksi Sosial juga dapat disimpulkan bahwa Interaksi Sosial lebih berdampak pada Perilaku Imitasi. Hasil penelitian juga menunjukan adanya hubungan yang Erat antara variabel terpaan media dan interaksi sosial berdasarkan nilai $\mathrm{R}$.
\end{abstract}

Kata kunci: Perilaku imitasi, remaja putri, youtube.

\begin{abstract}
In this study there are three variables: Media Exposed and Social Interaction as Independent variables and Imitation Behavior as Dependent variables. The purpose of this study are: (1) To find out and analyze the influence of social media Youtube K-POP content on the behavior of imitation teenage girls. (2) To find out and analyze the influence of Social Interaction on the behavior of teenage girl imitations. (3) To find out and analyze the influence of social media Youtube $K$ $P O P$ content and Social Interaction on the imitation behavior of young women. The analytical tool used is multiple linear regression with the help of SPSS version 20 statistical software. The technique in sampling in this study was carried out with Instagram account followers @zonablackpink with 395 respondents used. The method used in this study is a quantitative method to determine the effect or also the relationship between two or more variables. Data collection techniques using observation, questionnaires (questionnaire) and literature. The hypothesis of this study is that there is a significant influence between exposure to media and social interaction on imitation behavior in adolescent girls. Among the effects of Media Exposure and Social Interaction it can also be concluded that Social Interaction has more impact on Imitation Behavior. The results also showed a close relationship between media exposure variables and social interaction based on $R$ values.
\end{abstract}

Keywords: Imitation behavior, young women, youtube.

\section{PENDAHULUAN}

Perilaku imitasi adalah seluruh kehidupan sosial itu sebenarnya berdasarkan faktor imitasi saja. Walaupun pendapat ini berat sebelah, namun peranan imitasi dalam interaksi sosial itu tidak kecil. Macam-macam perilaku imitasi menurut Gerungan (2004) dapat dilakukan dengan berbagai macam cara, seperti: Gaya berbicara, Gaya Berpakaian dan Cara menyatakan diri. ada beberapa faktor penyebab perilaku imitasi yang berhubungan dengan komunikasi seperti terpaan media, interaksi antar sosial, dan lingkungan keluarga. (penyebaran nilai-nilai) memainkan peran penting dalam transmisi sikap, persepsi, dan kepercayaan.

Berdasarkan hasil penelitian dan pembahasan yang telah diuraikan oleh Yudi Mahasiswa Program S1 Ilmu Komunikasi, Fakultas Ilmu Sosial dan Ilmu Politik, Universitas Mulawarman, disimpulkan bahwa perilaku imitasi remaja setelah menonton tayangan boy bandlgirl band Korea di Kbs Channel mengarah 
kepada perilaku imitasi yang sangat jauh yang bisa membuat perubahan jati diri dan membentuk sebuah identitas yang baru pada karakter remaja tersebut. Sama halnya dengan penelitian dari Siska Ratih Dewanti Skripsi ini melaporkan hasil penelitian dari analisis fenomenologi terhadap fashion komunitas penggemar girl band Korea SNSD, yaitu Sone di Kota Tegal. Fashion Sone menunjukkan bahwa ada pesan yang ingin disampaikan oleh mereka. Dengan pengamatan terhadap atribut fashion yang mereka gunakan, penelitian ini ingin memaknai bagaimana fashion bisa dijadikan sebuah sarana untuk mempresentasikan diri dan sebagai identitas Sone.

Terpaan informasi yang dilakukan di sebuah media mampu mendorong kesadaran simbolik, kemudian kesadaran ini menimbulkan kesadaran konsumtif, dan kesadaran konsumtif menggiring konsumen pada kesadaran aktual (perilaku) Effendy (2003) proses komunikasi massa dalam terpaan media akan menimbulkan efek tertentu.

Interaksi sosial adalah suatu hubungan antara dua atau lebih individu manusia, dimana kelakuan individu yang satu mempengaruhi, mengubah, atau memperbaiki kelakuan individu yang lain, atau sebaliknya. Tokoh lain yaitu Gillin dan Gillin menyatakan bahwa interaksi sosial adalah hubungan-hubungan sosial yang dinamis yang menyangkut hubungan antara orang-orang perorangan, antara kelompok-kelompok manusia, maupun antara orang perorangan dengan kelompok manusia.

Masa remaja adalah masa transisi yang ditandai oleh adanya perubahan fisik, emosi dan psikis. Masa remaja, yakni antara usia 12-22 tahun, adalah suatu periode masa pematangan organ reproduksi manusia, dan sering disebut masa pubertas. Masa remaja adalah periode peralihan dari masa anak ke masa dewasa.

Masuknya fenomena demam K-POP di Indonesia dimulai dengan masuknya drama Korea yang sangat disukai di Indonesia sebut saja drama boys before flower dan full house. Lalu mulailah menjamur fansfans K-POP di Indonesia. Blackpink adalah grup yang debut di tahun 2016 melalui lagu Boombayah dan Whistle.

Pada akhirnya tanggal 15 Juni 2018 melakukan comeback dengan lagu $d d u-d u d d u-d u$, grup wanita asal YG Entertainment dengan empat anggota ini membuat banyak orang terpukau dengan video klip maupun lagu tersebut. Bukan hanya di Korea lagu $d d u-d u d d u-d u$ juga menjadi lagu yang disenangi oleh masyarakat Indonesia. Ini terbukti dengan dijadikan Blackpink sebagai bintang tamu spesial di acara Shopee. Blink adalah sebutan untuk fans Blackpink.
Blackpink juga memiliki banyak penggemar di Indonesia Ini terbukti dengan penjualan kursi dalam acara 'Shopee Road To 12.12' yang ludes dalam hitungan menit.

Berdasarkan latar belakang di atas penulis tertarik untuk meneliti tentang "Pengaruh Terpaan Media Sosial Youtube dan Interaksi Antar Sosial terhadap Perilaku Imitasi Remaja Putri (studi video clip Blackpink DDU DU DDU DU)".

\section{KERANGKA TEORI}

\subsection{New Media}

Media baru adalah media yang berbasis internet dengan menggunakan komputer dan telepon genggam canggih. Dua kekuatan utama perubahan awalnya adalah komunikasi satelit dan pemanfaatan komputer.

\subsection{Media Sosial}

Media sosial mengajak siapa saja yang tertarik untuk berpartisipasi dengan memberi kontribusi dan feedback secara terbuka, memberi komentar, serta membagi informasi dalam waktu yang cepat dan tak terbatas. Media sosial adalah sebuah media online, dengan para penggunanya bisa dengan mudah berpartisipasi.

\subsection{Interaksi Sosial}

Interaksi sosial adalah suatu hubungan antara dua atau lebih individu manusia, dimana kelakuan individu yang satu mempengaruhi, mengubah, atau memperbaiki kelakuan individu yang lain, atau sebaliknya.

\subsection{Youtube}

Perusahaan ini didirikan pada tahun 2005 oleh Steve Chen (CTO mantan) dan Chad Hurley (mantan CEO). Youtube hari ini adalah anak perusahaan dari Internet pencari raksasa Google.

\subsection{Remaja}

Remaja yang juga disebut adolescence, berasal dari bahasa Latin adolescere yang artinya "tumbuh atau tumbuh untuk mencapai kematangan".

\subsection{Terpaan Media}

Werner J Severin dan James Q Tankard, Jr mengemukakan bahwa pengguna media oleh masyarakat dapat diklasifikasikan adanya kebutuhan dasar sosial dan psikologis yang didasari oleh media massa atau sumber-sumber lainnya yang mempengaruhi pola terpaan media yang menghasilkan kebutuhan, dan konsekuensi. 


\subsection{Perilaku Imitasi}

Perilaku mempunyai arti yang lebih konkret dari pada "jiwa" karena lebih konkret itu, maka perilaku lebih mudah dipelajari daripada jiwa dan melalui perilaku kita tetap akan dapat mempelajari jiwa, perilaku disini adalah perbuatan-perbuatan yang terbuka (overt) maupun yang tertutup (covert).

\section{TEORI}

\subsection{Model S-O-R}

Istilah-istilah yang digunakan dalam model ini adalah pertama stimulus (S), kedua organism (O), dan ketiga, respon (R). stimulus adalah rangsangan atau dorongan, sehingga unsur stimulus dalam teori ini merupakan perangsang berupa message (isi pernyataan). Organism adalah badan yang hidup, sudah berarti manusia atau dalam istilah komunikan, sehingga unsur organism dalam teori ini adalah receiver (penerimaan pesan). Sehingga respons yang dimaksud sebagai reaksi, tanggapan, jawaban, pengaruh, efek atau akibat jadi dalam teori ini unsur respon adalah efek (pengaruh).

\subsection{Teori Dampak Media}

Selain fungsi menghibur, media juga memiliki fungsi yang lebih serius yaitu meyakinkan. Meskipun fungsi media yang paling jelas adalah menghibur, fungsinya yang terpenting adalah meyakinkan (to persuade). Persuasi dapat datang dalam banyak bentuk: (1) mengukuhkan atau memperkuat sikap, kepercayaan, atau nilai seseorang; (2) mengubah sikap, kepercayaan atau nilai seseorang; (3) menggerakkan seseorang untuk melakukan sesuatu; dan (4) memperkenalkan etika, atau menawarkan sistem nilai tertentu.

\subsection{Teori Interaksi sosial}

Interaksi sosial individu berkembang karena adanya dorongan rasa ingin tahu terhadap segala sesuatu yang ada di dunia sekitarnya. Setiap individu ingin tahu bagaimana cara melakukan interaksi sosial secara baik dan aman dengan dunia sekitarnya, baik yang bersifat fisik maupun sosial. Syarat-syarat terjadinya interaksi sosial, Soekanto menyatakan bahwa suatu interaksi sosial tidak akan terjadi apabila tidak memenuhi dua syarat yaitu:

1) Adanya kontak sosial

2) Adanya komunikasi

Macam-macam perilaku imitasi menurut Gerungan (2004) dapat dilakukan dengan berbagai macam cara, seperti:
a. Gaya berbicara.
b. Gaya Berpakaian
c. Cara menyatakan diri

\subsection{Teori perilaku imitasi}

Sarwono (2004) perilaku mempunyai arti yang lebih konkret dari pada "jiwa". Karena lebih konkret itu, maka perilaku lebih mudah dipelajari daripada jiwa dan melalui perilaku kita tetap akan dapat mempelajari jiwa.

Macam-macam perilaku imitasi menurut Gerungan (2004) dapat dilakukan dengan berbagai macam cara, seperti:
a. Gaya berbicara
b. Gaya Berpakaian
c. Cara menyatakan diri

\subsection{Model Penelitian}

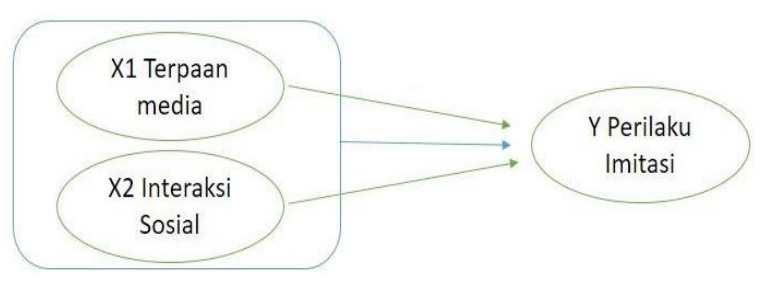

\section{METODE PENELITIAN}

\subsection{Subjek Penelitian}

Subjek dalam penelitian ini adalah Follower dari akun fanbase Instagram Blackpink dengan nama akun @ zonaBlackpink. Dalam penelitian ini, yang menjadi objek penelitian adalah tayangan video klip Blackpink " $D d u D u D d u D u$ ". Penelitian ini diklasifikasikan dalam penelitian kuantitatif deskriptif dengan menggunakan metode regresi. Metode penelitian kuantitatif. Berdasarkan sumbernya, data dibedakan atas data primer dan data sekunder:

1. Data Primer

Data primer merupakan data yang didapat dari sumber pertama baik individu atau perseorangan seperti hasil wawancara atau hasil pengisian kuesioner yang biasa dilakukan oleh peneliti. Terkait dengan penelitian ini, sumber data primer diperoleh dari responden melalui kuesioner yang diberikan oleh peneliti kepada remaja putri Follower dari akun fanbase Instagram Blackpink dengan nama akun @zonaBlackpink

2. Data Sekunder

Data sekunder adalah data yang diperoleh dari sumber kedua. Dapat dikatakan bahwa data 
sekunder yaitu data jadi atau data yang telah jadi. Dalam penelitian ini data sekundernya adalah data-data yang berkaitan dengan penelitian yang berasal dari berbagai sumber (seperti buku, jurnal, dan sebagainya). Dalam penelitian ini peneliti menggunakan sumber data yaitu:

a. Kuesioner merupakan teknik pengumpulan data yang dilakukan dengan cara memberi seperangkat pertanyaan atau pernyataan tertulis kepada responden untuk dijawabnya. Kuesioner digunakan bila jumlah responden cukup besar dan tersebar di wilayah yang luas.

b. Penelitian Kepustakaan (Library Research) yaitu penelitian yang dilakukan dengan menghimpun data-data dari buku-buku serta bacaan yang relevan serta mendukung penelitian.

\section{HASIL DAN PEMBAHASAN}

\subsection{Uji Asumsi Klasik}

\subsubsection{Uji Normalitas}

Hasil Uji Normalitas P-Plot

\section{Normal P.P Plot of Regression Standardized Residual}

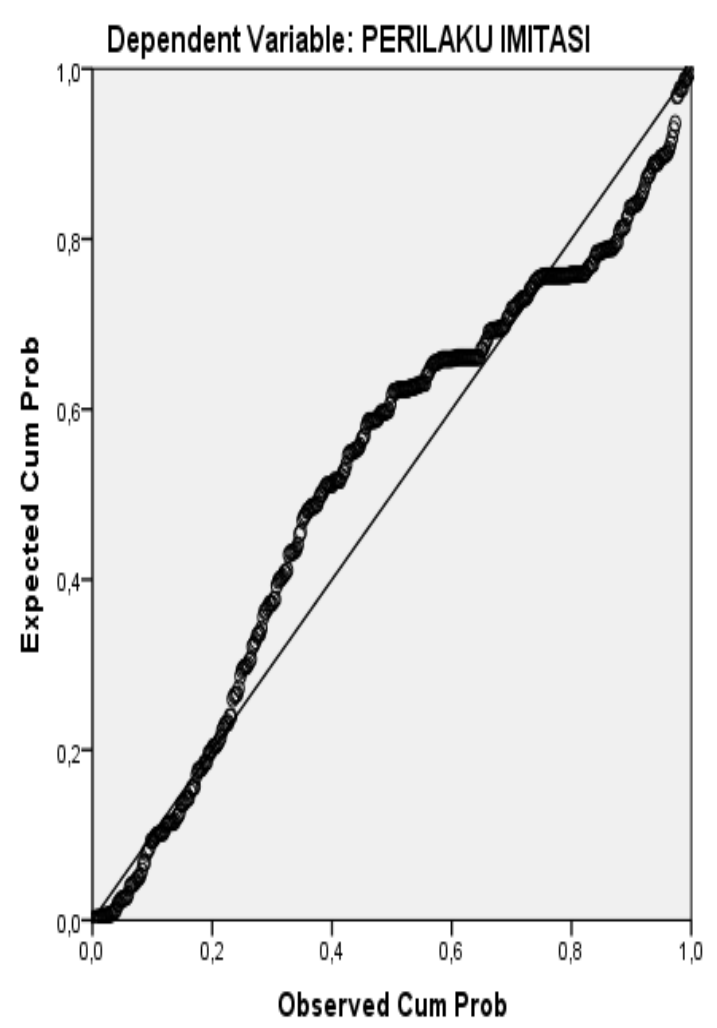

Berdasarkan hasil uji normalitas diketahui data dikatakan terdistribusi normal, karena data atau titik menyebar disekitar garis diagonal dan mengikuti arah garis diagonal.

\subsubsection{Uji Multikolinieritas}

Hasil Uji Multikolinieritas

\begin{tabular}{|c|c|c|c|c|c|c|c|c|}
\hline \multicolumn{9}{|c|}{ Coefficients" } \\
\hline \multirow{2}{*}{\multicolumn{2}{|c|}{ Model }} & \multicolumn{2}{|c|}{$\begin{array}{l}\text { Unstandardized } \\
\text { Coefficients }\end{array}$} & \multirow{2}{*}{\begin{tabular}{c|}
$\begin{array}{c}\text { Standardized } \\
\text { Coefficients }\end{array}$ \\
Beta
\end{tabular}} & \multirow[t]{2}{*}{$t$} & \multirow[t]{2}{*}{ Sig. } & \multicolumn{2}{|c|}{$\begin{array}{l}\text { Collinearity } \\
\text { Statistics }\end{array}$} \\
\hline & & B & Std. Error & & & & Tolerance & VIF \\
\hline 1 & (Constant) & $-19,092$ & 2,984 & & $-6,399$ & .000 & & \\
\hline & $\begin{array}{l}\text { TERPAAN } \\
\text { MEDIA }\end{array}$ & ,873 & 271 & 141 & 3,228 & .001 & .450 & 2,222 \\
\hline & $\begin{array}{l}\text { INTERAKSI } \\
\text { SOSIAL }\end{array}$ & 2,065 & .128 & .706 & 16,192 & .000 & .450 & 2,222 \\
\hline
\end{tabular}

Maka dapat ditarik kesimpulan bahwa:

1. Nilai tolerance $0.450>0.10$ maka artinya tidak terdapat multikolinieritas.

2. Nilai VIF $2,222<10.00$ maka artinya tidak terjadi multikolinieritas.

\subsubsection{Uji Heteroskedastisitas}

Hasil Uji Heteroskedastisitas

Scatterplot

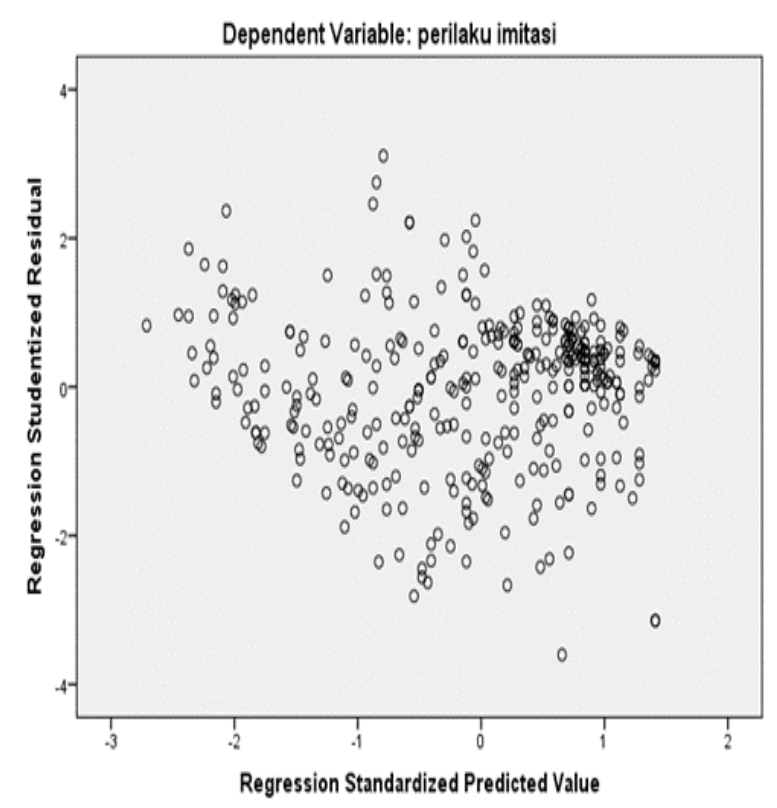

Berdasarkan pada gambar di atas, bahwa diketahui hasil analisisnya adalah:

1. Titik-titik data menyebar di atas dan di bawah atau di sekitar angka 0.

2. Titik-titik data tidak mengumpul hanya di atas atau di bawah saja.

3. Penyebaran titik-titik data tidak membentuk pola bergelombang melebar kemudian menyempit dan melebar kembali.

4. Penyebaran titik-titik data tidak berpola.

Maka, dari beberapa pernyataan diatas maka dapat disimpulkan bahwa tidak terjadi heteroskedastisitas. 


\subsubsection{Analisis Regresi Linear Sederhana}

Hasil Analisis Regresi Linier Sederhana X1 (Terpaan Media) Mempengaruhi Y (Perilaku Imitasi)

\begin{tabular}{|c|c|c|c|c|}
\hline \multicolumn{5}{|c|}{ Model Summary } \\
\hline Model & $\mathrm{R}$ & R Square & $\begin{array}{c}\text { Adjusted R } \\
\text { Square }\end{array}$ & $\begin{array}{l}\text { Std. Error of the } \\
\text { Estimate }\end{array}$ \\
\hline 1 & $.664^{*}$ & 441 & .439 & 13,54260 \\
\hline
\end{tabular}

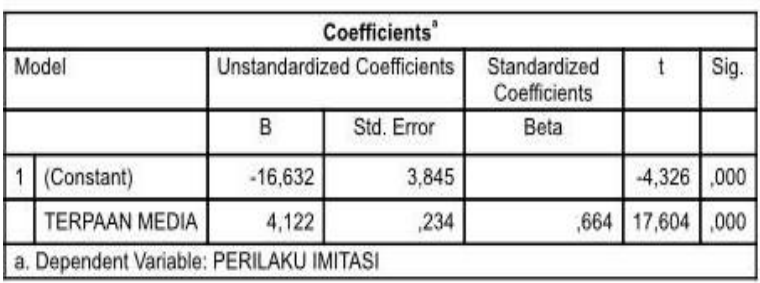

Sumber: Hasil Olah Data SPSS Peneliti

Perilaku imitasi $\mathrm{Y}=-16,632+0,441 \quad \mathrm{X} 1$ Terpaan media. dari penjelasan diatas diketahui nilai koefisien korelasi antar variabel terpaan media terhadap perilaku imitasi sebesar $0,441 \%$. Nilai ini mencerminkan bahwa terpaan media dengan perilaku imitasi mempunyai hubungan yang positif. Sedangkan hasil koefisien determinasi yang diperoleh yaitu sebesar 0,439 atau dalam persentase sebesar $43,9 \%$ nilai ini mencerminkan bahwa perilaku imitasi dipengaruhi oleh terpaan media sebesar 43,9\%.

Hasil Analisis Regresi Linier Sederhana X2 (Interaksi Sosial) Mempengaruhi Y (Perilaku Imitasi)

\begin{tabular}{|l|c|r|r|c|}
\hline \multicolumn{5}{|c|}{ Model Summary } \\
\hline Model & $\mathrm{R}$ & R Square & $\begin{array}{c}\text { Adjusted R } \\
\text { Square }\end{array}$ & $\begin{array}{c}\text { Std. Error of the } \\
\text { Estimate }\end{array}$ \\
\hline 1 & $.809^{3}$ &, 654 & \multicolumn{6}{|c|}{653} & 10,65481 \\
\hline a. Predictors: (Constant), INTERAKSI SOSIAL \\
\hline
\end{tabular}

\begin{tabular}{|c|c|c|c|c|c|}
\hline \multicolumn{6}{|c|}{ Coefficients ${ }^{a}$} \\
\hline \multirow[t]{2}{*}{ Model } & \multicolumn{2}{|c|}{ Unstandardized Coefficients } & \multirow{2}{*}{$\begin{array}{c}\begin{array}{c}\text { Standardized } \\
\text { Coefficients }\end{array} \\
\text { Beta }\end{array}$} & \multirow[t]{2}{*}{$t$} & \multirow[t]{2}{*}{ Sig. } \\
\hline & B & Std. Error & & & \\
\hline \begin{tabular}{l|l}
1 & (Constant)
\end{tabular} & $.12,867$ & 2,368 & & $-5,434$ & .000 \\
\hline INTERAKSI SOSIAL & 2,362 & ,087 &, 809 & 27,250 &, 000 \\
\hline
\end{tabular}

Sumber: Hasil Olah Data SPSS Peneliti

Perilaku imitasi $\mathrm{Y}=-12,867+0,654 \mathrm{X} 2$ Interaksi sosial. dari penjelasan diatas diketahui nilai koefisien korelasi antar variabel terpaan media terhadap perilaku imitasi sebesar $0,654 \%$. Nilai ini mencerminkan bahwa terpaan media dengan perilaku imitasi mempunyai hubungan yang positif. Sedangkan hasil koefisien determinasi yang diperoleh yaitu sebesar 0,653 atau dalam persentase sebesar $65,3 \%$ nilai ini mencerminkan bahwa perilaku imitasi dipengaruhi oleh terpaan media sebesar $65,3 \%$.

\subsubsection{Analisis Regresi Linier Berganda}

Hasil Analisis Regresi Linier Berganda

\begin{tabular}{|l|l|r|r|r|r|r|}
\hline \multicolumn{7}{|c|}{ Coefficients $^{*}$} \\
\hline \multicolumn{2}{|l|}{ Model } & \multicolumn{1}{|c|}{ Unstandardized Coefficients } & $\begin{array}{c}\text { Standardized } \\
\text { Coefficients }\end{array}$ & 1 & Sig. \\
\hline & B & Std. Error & Beta & & \\
\hline 1 & (Constant) & $-19,092$ & 2,984 & & $-6,399$ &, 000 \\
\hline & TERPAAN MEDIA &, 873 &, 271 &, 141 & 3,228 &, 001 \\
\hline & INTERAKSI SOSIAL & 2,065 &, 128 &, 706 & 16,192 &, 000 \\
\hline a. Dependent Variable: PERILAKU IMITASI &
\end{tabular}

Berdasarkan pada tabel diatas, yang dimana diperoleh data seperti diatas yang kemudian dimasukan sesuai rumus regresi linier berganda yang telah penulis cantumkan pada bab 3 maka akan diperoleh sebagai berikut:

$$
\begin{gathered}
\text { Rumus: } \\
\mathrm{Y}=\mathrm{a}+\mathrm{b}_{1} \mathrm{X}_{1}+\mathrm{b}_{2} \mathrm{X}_{2}
\end{gathered}
$$

Setelah memasukan data yang diperoleh ke dalam rumus maka akan didapat:

$$
\mathrm{Y}=-19,092+0.873 \mathrm{X}_{1}+2,065 \mathrm{X}_{2}
$$

Dari hasil diatas maka dapat ditarik beberapa kesimpulan, yaitu:

a. Constant sebesar -19,092 menyatakan bahwa jika nilai variabel X (Terpaan Media) dan variabel X2 (Interaksi Sosial) sama dengan nol, maka nilai variabel Y (Perilaku Imitasi) sebesar -19,092. dapat dikatakan konstanta dalam keadaan Negatif. Nilai konstanta negatif artinya jika tidak ada Variabel X, maka nilai Y akan turun. Berindikasi $\mathrm{X}$ memiliki pengaruh yang besar terhadap $\mathrm{Y}$.

b. Koefisien regresi b1 pada X1 (Terpaan Media) bernilai sebesar 0.873 menyatakan bahwa jika terdapat pengaruh dari Terpaan media setiap peningkatan 1 satuan pada variabel X1 (Terpaan Media) akan mempengaruhi variabel Y (Perilaku Imitasi) sebesar 0.398.

c. Koefisien regresi b2 pada X2 (Interaksi Sosial) bernilai sebesar 2,065 menyatakan bahwa jika terdapat pengaruh dari Interaksi Sosial setiap peningkatan 1 satuan pada variabel X1 (Terpaan Media) akan mempengaruhi variabel Y (Perilaku Imitasi) sebesar 2,065.

\subsection{Uji Hipotesis}

\subsubsection{Uji T}

Dasar pengambilan keputusan pada uji t adalah:

a. Jika nilai sig $<0,05$, atau $t$ hitung $>\mathrm{t}$ tabel maka terdapat pengaruh variabel $\mathrm{X}$ terhadap variabel $\mathrm{Y}$.

b. Jika nilai sig $>0,05$, atau $t$ hitung $<\mathrm{t}$ tabel maka tidak terdapat pengaruh variabel $\mathrm{X}$ terhadap variabel Y. 
$\mathrm{T}$ hitung $=\mathrm{t}(\alpha / 2 ; \mathrm{n}-\mathrm{k}-1)$ Jika menurut rumus diatas, maka dalam penelitian ini diperoleh data sebagai berikut, $\mathrm{t}(0,025 ; 393)=1,966$ yang berarti nilai $\mathrm{t}$ tabel pada penelitian ini adalah 1.966 .

\begin{tabular}{|c|c|c|c|c|c|c|}
\hline \multicolumn{7}{|c|}{ Hasil Uji T } \\
\hline \multicolumn{7}{|c|}{ Coefficientsa } \\
\hline \multirow{2}{*}{\multicolumn{2}{|c|}{ Model }} & \multicolumn{2}{|c|}{ Unstandardized Coefficients } & $\begin{array}{l}\text { Standardized } \\
\text { Coefficients }\end{array}$ & $t$ & Sig. \\
\hline & & B & Std. Error & Beta & & \\
\hline 1 & (Constant) & $-19,092$ & 2,984 & & $-6,399$ & .000 \\
\hline & TERPAAN MEDIA & .873 & .271 & 141 & 3,228 & .001 \\
\hline & INTERAKSI SOSIAL & 2.065 & .128 & .706 & 16,192 & .000 \\
\hline
\end{tabular}

Adapun hipotesis pada penelitian ini adalah:

$\mathrm{H}_{0} 2$ : Tidak terdapat pengaruh terpaan media dan interaksi sosial terhadap perilaku Imitasi remaja putri

H2 : Terdapat pengaruh terpaan media dan interaksi sosial terhadap perilaku imitasi remaja putri.

H3 : Terdapat pengaruh interaksi sosial terhadap perilaku imitasi.

Berdasarkan tabel di atas, dapat disimpulkan dari hasil uji t, maka akan mendapatkan hasil hipotesis sebagai berikut:

1. Terpaan Media (X1) terhadap Perilaku Imitasi (Y) Berdasarkan pada tabel 4.29 diketahui bahwa nilai $\mathrm{t}$ hitung untuk pengaruh Terpaan Media (X1) adalah 3,228 > t tabel 1.966 dan nilai Sig. $0.001<$ 0.05. Maka Ho2 ditolak dan $\mathrm{H} 2$ diterima. Sehingga dapat disimpulkan bahwa Terpaan Media (X1) berpengaruh positif dan signifikan terhadap Perilaku Imitasi (Y).

2. Interaksi Sosial (X2) terhadap Perilaku Imitasi (Y) Berdasarkan pada tabel 4.29 diketahui bahwa nilai t hitung untuk pengaruh Interaksi Sosial (X2) adalah 16,192 > t tabel 1.966 dan nilai Sig. 0.000 $<0.05$. Maka Ho2 ditolak dan H3 diterima. Sehingga dapat disimpulkan bahwa Interaksi Sosial (X2) berpengaruh positif dan signifikan terhadap Perilaku Imitasi (Y).

\subsubsection{Uji F}

Dasar pengambilan keputusan pada uji $\mathrm{f}$ adalah:

a. Jika nilai sig $<0,05$, atau F hitung $>\mathrm{F}$ tabel maka terdapat pengaruh variabel $\mathrm{X}$ secara simultan terhadap variabel $\mathrm{Y}$.

b. Jika nilai sig $>0,05$, atau $\mathrm{F}$ hitung $<\mathrm{F}$ tabel maka tidak terdapat pengaruh variabel $\mathrm{X}$ secara simultan terhadap variabel Y.

$\mathrm{F}$ hitung $=\mathrm{F}(\mathrm{k} ; \mathrm{n}-\mathrm{k})$ Jika menurut rumus diatas, maka dalam penelitian ini diperoleh data sebagai berikut $F$ $(2 ; 393)=2,627$, yang berarti nilai $\mathrm{f}$ hitung pada penelitian ini adalah 2,627.

Hasil Uji F
\begin{tabular}{|l|l|r|r|r|r|r|}
\hline \multicolumn{7}{|c|}{ ANOVA" } \\
\hline \multicolumn{2}{|c|}{ Model } & Sum of Squares & df & Mean Square & \multicolumn{1}{c|}{ F } & Sig. \\
\hline 1 & Regression & 85724,377 & 2 & 42862,189 & 389,030 & $000^{\circ}$ \\
\hline & Residual & 43189,461 & 392 & 110,177 & & \\
\hline & Total & 128913,838 & 394 & & & \\
\hline \multicolumn{2}{|l|}{ a. Dependent Variable: PERILAKU IMITASI } \\
\hline
\end{tabular}

Adapun hipotesis pada penelitian ini adalah:

$\mathrm{H}_{0} 1$ : Tidak terdapat pengaruh Terpaan Media Dan Interaksi Sosial Terhadap Perilaku Imitasi Remaja Putri.

H1 : Terdapat pengaruh Terpaan Media Dan Interaksi Sosial Terhadap Perilaku Imitasi Remaja Putri.

Berdasarkan pada tabel diatas diketahui bahwa nilai $\mathrm{f}$ hitung pada penelitian pengaruh Terpaan Media dan Interaksi Sosial Terhadap Perilaku Imitasi (Y) adalah $389,030>$ f tabel 2,627 dan nilai Sig. $0.000<0.05$. Maka Ho1 ditolak dan H1 diterima. Sehingga dapat disimpulkan bahwa pengaruh terpaan media dan interaksi sosial berpengaruh positif dan signifikan terhadap perilaku imitasi (Y) secara simultan atau bersama-sama.

\subsubsection{Uji Korelasi dan Koefisien Determinasi (R)}

Hasil Uji Korelasi dan Koefisien Determinasi X1 Terhadap Y

\begin{tabular}{|c|c|c|c|c|c|c|c|c|c|}
\hline \multicolumn{10}{|c|}{ Model Summary } \\
\hline \multirow{2}{*}{$\begin{array}{l}\text { Mod } \\
\text { el }\end{array}$} & $R$ & $R$ & Adjusted R & Std. Error & \multicolumn{5}{|c|}{ Change Statistics } \\
\hline & & & & & $\begin{array}{l}\text { R Square } \\
\text { Change }\end{array}$ & $\begin{array}{c}F \\
\text { Change }\end{array}$ & df1 & $d \mathfrak{d} 2$ & $\begin{array}{c}\text { Sig. F } \\
\text { Change }\end{array}$ \\
\hline 1 & $.663^{\circ}$ &, 440 & ,438 & 12,67892 &, 440 & 308,226 & & 393 &, 000 \\
\hline
\end{tabular}

Sumber: Hasil Olah Data SPSS Peneliti

Berdasarkan pada di atas menjelaskan bahwa besarnya pengaruh Terpaan Media sosial media Youtube terhadap Perilaku Imitasi diketahui bahwa:

1. Nilai R: 0,663. Artinya, hubungan antara pengaruh Terpaan Media terhadap Perilaku Imitasi dipengaruhi sebesar 0,663 (66,3\%) oleh terpaan media sosial. Kekuatan hubungan yang menunjukan derajat koefisien asosiasi (korelasi) dengan rentang 0,60 - 0,799 memiliki hubungan yang Erat.

2. Nilai R Square 0,440 berarti $(44,0 \%)$ nilai tersebut menunjukan bahwa terpaan media memberikan dampak $44 \%$ terhadap perilaku imitasi remaja putri, sedangkan sisanya 56\% (100-44) dipengaruhi oleh faktor lain selain variabel ini. 
Hasil Uji Korelasi dan Koefisien Determinasi X2 Terhadap Y

Model Summary

\begin{tabular}{l|c|r|r|r|r|r|r|r|r}
\hline $\begin{array}{l}\text { Mod } \\
\text { el }\end{array}$ & $R$ & $\begin{array}{c}\text { R } \\
\text { Square }\end{array}$ & $\begin{array}{r}\text { Adjusted } \\
\text { R Square }\end{array}$ & $\begin{array}{r}\text { Std. Error } \\
\text { of the } \\
\text { Estimate }\end{array}$ & \multicolumn{5}{|c}{ Change Statistics } \\
\hline & & & & & $\begin{array}{r}\text { R Square } \\
\text { Change }\end{array}$ & $\begin{array}{c}F \\
\text { Change }\end{array}$ & df1 & df2 & $\begin{array}{c}\text { Sig. F } \\
\text { Change }\end{array}$ \\
\hline 1 &, $849^{\circ}$ &, 720 &, 720 & 8,95746 &, 720 & 1011,92 & 1 & 393 &, 000 \\
\hline
\end{tabular}

Sumber: Hasil Olah Data SPSS Peneliti

Berdasarkan pada di atas menjelaskan bahwa besarnya pengaruh Interaksi Sosial terhadap Perilaku Imitasi diketahui bahwa:

1. Nilai R: 0,849 . Artinya, hubungan antara pengaruh Interaksi Sosial terhadap Perilaku Imitasi dipengaruhi sebesar $0,849(84,9 \%)$ oleh terpaan interaksi sosial. Kekuatan hubungan yang menunjukan derajat koefisien asosiasi (korelasi) dengan rentang 0,80 - 1,00 memiliki hubungan yang Sangat Erat.

2. Nilai R Square 0,720 berarti (72\%) nilai tersebut menunjukan bahwa interaksi sosial memberikan dampak $72 \%$ terhadap perilaku imitasi remaja putri, sedangkan sisanya $28 \%$ (100-72) dipengaruhi oleh faktor lain selain variabel ini.

Hasil Uji Korelasi dan Koefisien Determinasi X1 dan X2

\begin{tabular}{|c|c|c|c|c|c|c|c|c|c|}
\hline \multicolumn{10}{|c|}{ Terhadap Y } \\
\hline \multicolumn{10}{|c|}{ Model Summary } \\
\hline \multirow{2}{*}{$\begin{array}{l}\text { Mod } \\
\text { el }\end{array}$} & $R$ & $R$ & Adjusted R & Std. Error & \multicolumn{5}{|c|}{ Change Statistics } \\
\hline & & & & & $\begin{array}{c}\text { R Square } \\
\text { Change }\end{array}$ & $\begin{array}{c}F \\
\text { Change }\end{array}$ & df1 & $\mathrm{df} 2$ & $\begin{array}{l}\text { Sig. F } \\
\text { Change }\end{array}$ \\
\hline 1 & $.815^{\circ}$ & 665 & 663 & 10,49653 & 665 & 389,030 & 2 & 392 &, 000 \\
\hline a. Pre & ors: & instant & ITERAKSI & SIAL, TEF & PAAN MEDIA & & & & \\
\hline
\end{tabular}

Sumber: Hasil Olah Data SPSS Peneliti.

Berdasarkan pada di atas menjelaskan bahwa besarnya pengaruh Terpaan Media sosial media Youtube dan Interaksi Sosial terhadap Perilaku Imitasi diketahui bahwa:

1. Nilai R: 0,815 . Artinya, hubungan antara pengaruh Terpaan Media dan Interaksi Sosial terhadap Perilaku Imitasi dipengaruhi sebesar 0,815 $(81,5 \%)$ oleh terpaan media sosial dan interaksi sosial. Kekuatan hubungan yang menunjukan derajat koefisien asosiasi (korelasi) dengan rentang $0,60-0,799$ memiliki hubungan yang Erat.

2. Nilai R Square 0,665 berarti $(66,5 \%)$ nilai tersebut menunjukan bahwa terpaan media dan interaksi sosial memberikan dampak $66,5 \%$ terhadap perilaku imitasi remaja putri, sedangkan sisanya $33,5 \%(100-66,5)$ di pengaruhi oleh faktor lain selain variable ini.

\section{KESIMPULAN \& SARAN}

\subsection{KESIMPULAN}

Berdasarkan hasil dari analisis data dan pembahasan, dapat diambil kesimpulan bahwa variabel dependen X1 (Terpaan Youtube) dan X2 (Interaksi Sosial) berpengaruh positif dan signifikan terhadap variabel independen Y (Perilaku Imitasi) yang dilakukan terhadap remaja putri yang mengikuti akun Instagram @ZonaBlackpink.

Berdasarkan hasil penelitian diketahui bahwa pengaruh Terpaan Media (X1) Ho2 ditolak dan H2 diterima. Sehingga dapat disimpulkan bahwa Terpaan Media (X1) berpengaruh positif dan signifikan terhadap Perilaku Imitasi (Y). Dan Berdasarkan hasil penelitian diketahui bahwa pengaruh Interaksi Sosial (X2) adalah Ho2 ditolak dan H3 diterima. Sehingga dapat disimpulkan bahwa Interaksi Sosial (X2) berpengaruh positif dan signifikan terhadap Perilaku Imitasi (Y).

Berdasarkan pengujian diketahui bahwa penelitian pengaruh terpaan media dan interaksi sosial terhadap perilaku imitasi (Y). Adalah Hol ditolak dan H1 diterima. Sehingga dapat disimpulkan bahwa pengaruh Terpaan Media Dan Interaksi Sosial berpengaruh positif dan signifikan terhadap Perilaku Imitasi (Y) secara simultan atau bersama-sama. Diantara pengaruh Terpaan Media dan Interaksi Sosial juga dapat disimpulkan bahwa Interaksi Sosial lebih berdampak pada Perilaku Imitasi hal tersebut dapat dilihat pada nilai R Square Uji Korelasi dan Koefisien Determinasi X2 Terhadap Y. Hasil penelitian juga menunjukan adanya hubungan yang Erat antara variabel terpaan media dan interaksi sosial berdasarkan nilai $\mathrm{R}$.

\subsection{SARAN}

A. Bagi Peneliti Selanjutnya

Terkait dengan keterbatasan penelitian ini, maka peneliti selanjutnya diharapkan dapat jauh lebih memperluas Batasan populasi dan sampel dalam penelitiannya sehingga hasil yang diperoleh lebih konsisten dijadikan acuan penelitian dengan bahasan atau topik yang sama, kembangkan dengan pemilihan objek penelitian yang lain atau menambah variable seperti misalkan efek moderat dan lain-lain.

B. Bagi Remaja putri

Terkait dengan penelitian ini, tentu menyenangi sesuatu hal pasti memiliki berbagai pengaruh bagi remaja. Tetapi remaja harus lebih selektif dalam 
menyikapinya. Jika membawa pengaruh positif seperti lebih bersosialisasi maka harus dipertahankan. Tetapi jika memiliki dampak negatif meniru sikap yang berlawanan dengan etika dan budaya di Indonesia maka harus ditinggalkan

\section{DAFTAR PUSTAKA}

Abu, Ahmadi.2007. Psikologi Sosial. Jakarta: Rineka Cipta.

Adi Fahrudin, Ph.D.2009. Pengantar Kesejahteraan Sosial, Yogyakarta: Pustaka Pelajar

Ali, Mohammad. dan Mohammad Asrori. 2012. Psikologi Remaja Perkembangan Peserta Didik. Jakarta: PT. Bumi Aksara.

Andreas, Kaplan M., Haenlein Michael 2010. "Users of the world, unite! The challenges and opportunities of social media". Business Horizons 53.

Ardianto, Elvinaro. 2007. Komunikasi Massa Suatu Pengantar. Bandung: Simbiosa Rekatama

Arikunto, Suharsimi. 2002. Prosedur PenelitianSuatu Pendekatan Praktek, Cetakan Kedua Belas (Edisi Revisi V). Jakarta: PT. Rineka Cipta.

Arikunto, S. 2010. Prosedur Penelitian Suatu Pendekatan Praktik. Jakarta: Rineka Cipta

Baran, Stanley j.2012. Pengantar Komunikasi Massa Melek Media dan Budaya.Jakarta: PT Gelora Aksara Pratama.

Basrowi dan Suwandi. 2008. Memahami Penelitian Kualitatif. Jakarta: Rineka Cipta

Burton, Graeme. 2012. Media dan Budaya Populer: Yogyakarta: Jalasutra

Creeber, G. and Martin, R., (ed)., 2009, Digital Cultures: Understanding New Media, BerkshireEngland: Open University Press.

Creswell, J. W. (2010). Research design: pendekatan kualitatif, kuantitatif, dan mixed. Yogyakarta: PT Pustaka Pelajar.

Dijk, Van. 2006. The Network Society. London: SAGE Publications.

Effendy, Onong Uchjana. 2003. Ilmu Teori dan Filsafat Komunikasi. Bandung: Citra Aditya Bakti.

Flew, T. 2008. New Media: an introduction. New York: Oxford University Pers.

Gerungan, W. A. 2004. Psikologi Sosial, Bandung: PT Refika Aditama.

Ghozali, Imam. 2006. Aplikasi Analisis Multivariate Dengan Program SPSS. Cetakan Keempat. Semarang: Badan Penerbit Universitas Diponegoro.

Hasan, Iqbal. 2002. Pokok-Pokok Materi Metodologi Penelitian dan Aplikasinya. Jakarta: Ghalia Indonesia

Hurlock, Elizabeth B. 1980. Psikologi Perkembangan: Suatu Pendekatan Sepanjang Rentang Kehidupan. Jakarta: Gramedia.
Husein Umar, 2004, Riset Sumber Daya Manusia Dalam Organisasi, Cetakan Keempat, PT. Gramedia Pustaka Utama, Jakarta.

Husein Umar, 2004, Metode Penelitian Untuk Skripsi Dan Tesis Bisnis, Cet. ke 6, Jakarta: PT Raja Grafindo Persada.

Joko Subagyo, P. 2006. Metode Penelitian Dalam Teori Dan Praktek. Rineka Cipta. Jakarta.

Kriyantono, Rahmat. 2006. Teknik Praktis Riset Komunikasi. Jakarta: PT. Kencana Perdana.

Littlejohn, Stephen W \& Karen A. Foss.2009. Teori Komunikasi, edisi 9. Jakarta: Salemba Humanika.

Lievrouw, L.A. 2011. Alternative and Activist New Media. Cambridge: Polity Press.

Morissan. 2012. Metode Penelitian Survey. Jakarta: Kencana Prenada Media Group.

Mulyana, Deddy, 2003, Metodologi Penelitian Kualitatif - Paradigma Baru Ilmu Komunikasi dan Ilmu Sosial Lainnya, Bandung: PT. Remaja Rosdakarya.

McQuail, Denis. 2011. Teori Komunikasi. Jakarta: Salemba Humanika

Mondry. 2008. Pemahaman Teori dan Praktek Jurnalistik. Penerbit: Ghalia Indonesia.

Morissan. 2012. Metode Penelitian Survey. Jakarta: Kencana Prenada Media Group.

Notoatmodjo, Soekidjo. 2003. Pendidikan Dan Perilaku Kesehatan. Rineka Cipta. Jakarta.

Nurgiyantoro, Burhan. 2012. Penilaian Pembelajaran Bahasa. Yogyakarta: BPFE.

Puntoadi, Danis. 2011. Meningkatkan Penjualan Melalui Social Media. Elex Gramedia.

Rakhmat, Jalaludin. 2009. Metode Penelitian Koтunikasi. Bandung: PT Remaja Rosdakarya

Santoso, Slamet. 2009. Dinamika Kelompok. Jakarta: PT. Raja Grafindo Persada

Sarwono, Sarlito Wirawan. 1983. Teori-Teori Psikologi Sosial. Jakarta: Balai Pustaka

Sarwono, W. Sarlito, 2004. Psikologi remaja. Jakarta. PT RajaGrafindo Persada.

Severin, Werner J. \& James W. Tankard, Jr., Teori Komunikasi Sejarah, Metode dan Terapan di dalam Media Massa edisi kelima, Kencana Prenada Media Group, Jakarta, 2011.

Siregar, Syofian. 2013. Metode Penelitian Kuantitatif. Jakarta: PT Fajar Interpratama Mandiri.

Siregar, S., 2012, Metode Penelitian Kuantitatif, Kencana, Jakarta

Soekanto, Soejono. 1990. Sosiologi Suatu Pengantar. Jakarta. PT Raja Grafindo Persada.

Sugiyono. 2003. Metode Penelitian Bisnis. Edisi 1 Alfabeta: Bandung. 
Sugiyono. 2008. Metode Penelitian Bisnis. Alfabeta: Bandung.

Sugiyono. 2011. Metode Penelitian Kuantitatif dan Kualitatif dan $R \& D$. Bandung: CV Alfabeta.

Sugiyono. 2014. Metode Penelitian Pendidikan Pendekatan Kuantitatif, Kualitatif, dan R\&D. Bandung: Alfabeta.

Suryabrata, S. 2003. Metodologi Penelitian, cetakan keempat belas. Jakarta: PT. Raja Grafindo Persada.

Syofian, Siregar. 2014. Metode Penelitian Kuantitatif. Jakarta: Kencana.

Vivian, John.2008. The Media of Mass Communication, 8th ed. Boston: Pearson Education

Walgito. 2006. Bimbingan Konseling di Sekolah. Yogyakarta: Andi Offset

Widyastuti Y, Rahmawati A, Purnamaningrum YE. 2009. Kesehatan Reproduksi. Yogyakarta: Fitramaya.

Widyatama, Rendra. 2009. Buku Pengantar Periklanan, cet 6. Yogyakarta: Pustaka Book Publisher.
Darmista, Ajeng. "Agresi Budaya Korea Melalui KPop di Indonesia". Kompasiana, 24 Januari 2015. https://www.kompasiana.com/ajenkoya/agresibudaya-Koreamelalui-k-pop-diindonesia _54f90928a33311b918 8b4bcf (diakses pada tanggal 18 February 2019 pukul $19.10 \mathrm{WIB}$ )

Pinem, W. D., \& Ikhsan, M. (2012). Korean Wave dan Peningkatan Perekonomian Korea Selatan. Diakses Juli 13, 2017, dari Seni Berpikir Ilmu dan Teknologi: https://www.seniberpikir.com/ Korean-wave-dan-peningkatan-perekonomianKorea-selatan

http://journals.itb.ac.id/index.php/sostek/article/view/1 105 diakses pada 2 februari 2019

https://www.viva.co.id/showbiz/musik/1104192-

konser-Blackpink-di-indonesia-resmi-digelar-2hari diakses pada 4 Februari 2019

http://www.jurnalkomputer.com/attachments/article/8 32/YOUTUBE.pdf_diakses pada tanggal 8 Juni 2019 pukul 19.25 WIB 